\title{
Rigging the nose: a pilot study using barbed sutures in patients with deviated nose
}

\author{
Yves L. J. Goffart ${ }^{1}$ (D) $\cdot$ Sarah Remacle ${ }^{1}$ \\ Received: 30 March 2020 / Accepted: 15 June 2020 / Published online: 1 July 2020 \\ (C) The Author(s) 2020
}

\begin{abstract}
Background A deviated nose is a very common developmental feature in Caucasian populations and represents a frequent indication for rhinoplasty, either functional or esthetic. We aim to assess the pattern of nasal axis stabilization after rhinoplasty in the deviated nose on the basis of anthropometric measurements: median face axis (MFA), interpupillary meridian axis (IMA), and scoliosis angle (SA); to study possible effects of rigging the nose in the midfacial soft tissues using absorbable soft sutures; to investigate possible side effects.

Methods Seventy patients with a non-traumatic deviated nose ( $n=50$ as control group, $n=20$ as treated group with placement of barbed suture in the midfacial soft tissues) underwent rhinoplasty procedures. We retrospectively examined the pattern of deviation recurrence over time in a consecutive series of 70 non-traumatic patients undergoing primary esthetic or functional rhinoplasty ( $n=50$ as control group, $n=20$ as treated group with placement of barbed suture in the midfacial soft tissues). Patients were followed up at 1 week, 2 weeks, 1 month, 3 months, and 1 year postoperatively.

Results Ninety-three percent (65/70) of the patients had an asymmetric face after comparing the two anthropometric angles MFA and IMA. Overcorrection of NA at one week postoperatively was observed in $1.25 \%$ and $35.7 \%$ of patients in the control and treated groups, respectively $(p=0.006)$. MFA shifted from $4.16^{\circ} \pm 3.1^{\circ}$ preoperatively to $1.2^{\circ} \pm 1.4^{\circ}$ at 1 week, $1.0^{\circ} \pm 1.1^{\circ}$ at 2 weeks, $1.1^{\circ} \pm 1.4^{\circ}$ at 1 month, $1.1^{\circ} \pm 1.5^{\circ}$ at 3 months, and $1.7^{\circ} \pm 2^{\circ}$ at 1 year in the control group. In the treated group, MFA shifted from $5.7^{\circ} \pm 2.9$ preoperatively to $-0.34^{\circ} \pm 2.9^{\circ}$ at 1 week, $1.0^{\circ} \pm 1.1^{\circ}$ at 2 weeks, $0.59^{\circ} \pm 0.96^{\circ}$ at 1 month, $1.22^{\circ} \pm 0.83^{\circ}$ at 3 months, and $1.63^{\circ} \pm 0.8^{\circ}$ at 1 year. Differences between the groups were significant at 1 week $(p=0.02)$, but differences were not significant at 2 weeks, 1 month, 3 months, and 1 year.

Conclusions This pilot study demonstrates that the progressive re-deviation pattern is altered during the first weeks after surgery in the barbed sutures group. Absorbable barbed sutures in facial soft tissues are well tolerated. Longer lasting sutures may help to obtain definite advantage.

Level of evidence: Level IV, therapeutic study.
\end{abstract}

Keywords Rhinoplasty $\cdot$ Deviated nose $\cdot$ Barbed suture $\cdot$ Outcomes $\cdot$ Recurrence

\section{Introduction}

A deviated nose is a very common developmental feature in Caucasian populations and represents a frequent indication for

The results of this study have been presented by Yves LJ Goffart at the 12th International Symposium of Facial Plastic Surgery on October 17, 2018, Dallas, TX.

Yves L. J. Goffart

yves.goffart@chrcitadelle.be

1 Department of ENT and Head Neck/MaxilloFacial Surgery, CHR Citadelle, B 4000 Liege, Belgium rhinoplasty, either functional or esthetic. Nasal axis (NA) deviation is often associated with midfacial asymmetry [1-3]. Evolutionary biologists postulate that facial symmetry represents a sign of health and genetic quality, and therefore is attractive $[4,5]$.

NA deviations are classified as linear, C-shaped, or Sshaped. Midfacial asymmetry may be present in any of the three dimensions of the face while maxillary hypoplasia is defined as a decrease in all three planes $[6,7]$.

Although the central role of septoplasty for adequate correction of the deviated nose is acknowledged, rationales or patterns for recurrences after proper rhinoplasty remain unclear [8-10]. Surgeons have theorized that recurrence over 
months depends entirely on the cartilaginous "memory" structure of the nasal pyramid [11-13].

Most patients with a non-traumatic deviated nose present with an asymmetric face $[3,6,7,12]$. This asymmetry is present both in the maxillary support and in facial soft tissues. As a result, when the nose is set in the midline after rhinoplasty, additional tension is created on the hypoplastic side of the face, whereas the wider side of the face loosens. The resulting imbalance between the sides of the face will even increase with facial expressions. It is unclear whether these tensile forces in facial soft tissues, fascia, and muscles play a role in the progressive re-deviation process over several months until healing of bony and cartilaginous structures is completed and definitive stretching of soft tissues is obtained [3].

Any method of counteracting the postoperative imbalance in facial soft tissues might help in obtaining better results. In this perspective, we aimed to investigate the safety and potential efficacy of a novel surgical technique for rigging the nose in the midline using barbed sutures.

\section{Material and Methods}

We conducted a retrospective photographic analysis of 70 consecutive patients who complained of a significantly deviated or crooked nose. Patients who underwent esthetic or functional primary rhinoplasty, without a significant history of trauma, were included in this retrospective review. In this pilot study, 50 patients were included in the control group, and 20 patients were included in the barbed suture treatment group. The senior author performed all operations with an open rhinoplasty approach using modern advanced techniques for correcting asymmetries in the nose and releasing all possible spring mechanisms.

High-resolution photographs were taken with a professional digital camera (Canon EOS 7D and 35-105 mm f/4 Canon lens, Canon Inc., Tokyo, Japan). Baseline and postoperative photographs at 1 week, 2 weeks, 1 month, 3 months, and 1 year were analyzed. One patient who later sustained trauma and required surgical reduction at 6 months was excluded and two patients (one in the control group and one in the treated group) were lost to follow-up.

Photographs were assessed using the GIMP 2.8.22 (Gnome Foundation, USA) software by both authors. Three anthropometric measurements of the NA were obtained for each patient at each step (Fig. 1):

- An imaginary sagittal line beginning from the central hairline point and crossing the glabella, the central point of the Cupid's bow on the upper lip, and the bottom of the chin was drawn. The angle between this meridian and a line connecting the nasion $(\mathrm{N})$ to the nasal tip $(\mathrm{T})$ was defined as the median face axis (MFA).

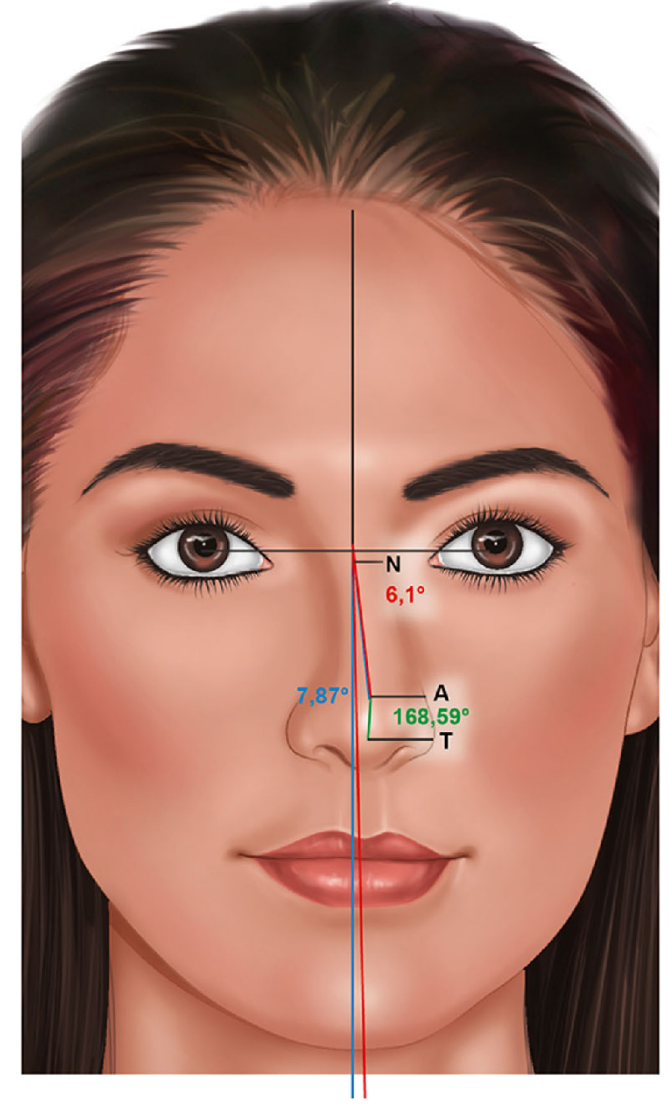

Fig. 1 Measurement of the median face axis (MFA, blue line), interpupillary meridian axis (IMA, red line), and scoliosis angle (SA, green line). Nasion $(\mathrm{N})$, apex of scoliosis (A), and tip of the nose (T)

- A horizontal interpupillary line was drawn, and a perpendicular line was drawn from the middle of this line. The angle between this meridian and a line connecting the nasion $(\mathrm{N})$ to the nasal tip $(\mathrm{T})$ was defined as the interpupillary meridian axis (IMA).

- NA is evaluated relative to IMA and MFA, and $0^{\circ}$ indicated that no deviation was measurable. Given that the variable of interest was the degree and not the laterality of asymmetry, we did not distinguish left and/or right deviations.

- The deviation angles of the $\mathrm{C}$-shaped crooked nose were measured as follows. First, a line was drawn from $\mathrm{N}$ to the apex of the convexity (A). From this point, a second line was drawn to the tip of the nose, and the scoliosis angle (SA) was measured; $180^{\circ}$ indicated that the nose was perfectly straight, and no scoliosis was measurable. In the Cshaped nose, NA was assessed until the apex of convexity (A) using MFA and IMA coordinates.

\section{Surgical technique}

At the end of the open rhinoplasty procedure, before closing the incision, bidirectional 2-0 poliglecaprone barbed sutures were placed through the nasal septal dorsum at two points, 
with one point near the cartilaginous osseous junction and one point more caudally in the cartilaginous dorsum. The suture was then passed through the soft tissues of the midface, exiting contra-laterally to the preexistent nasal deviation (Fig. 2). Delivery to the middle of the cheek was obtained by a $20-\mathrm{G} 90-\mathrm{mm}$ spinal needle. The tension was adjusted before placing the splint, and a medical tape was placed on the emergence of the suture on the cheek. At postoperative day 2 , the patient was seen in the office for removal of light nasal packing, and the sutures were cut at the skin level.

\section{Statistical analysis}

Quantitative variables are expressed as median, mean, standard deviation, and interquartile rank. Angle distributions were assessed by $t$ test (paired samples) or Wilcoxon test (non-parametric samples). Evolution of angles over time after surgery was analyzed using a generalized linear mixed (GLMM) model. The SAS 9.4 software was used for the analysis.

\section{Results}

Among the 70 enrolled patients, IMA and MFA significantly differed in 65 patients $(93 \%)$ at baseline $(p=0.026)$. The relationship between MFA and SA $(R$ Spearman $=0.71$, $p<0.0001)$ and between IMA and SA $(R$ Spearman $=-$ $0.56, p<0.0001$ ) showed a significantly increasing trend. The treated group had significantly higher MFA than the control group $\left(\mathrm{MFA}=5.7^{\circ} \pm 2.9^{\circ}\right.$ vs. $\left.4.16^{\circ} \pm 3.1^{\circ} ; p=0.018\right) . \mathrm{SA}$ was not significantly different between the two groups (treated group, $170.8^{\circ} \pm 6.1^{\circ}$ vs. control group, $171.7^{\circ} \pm 6.2^{\circ}$ ). Figure $3 \mathrm{a}$ presents the distribution of MFA and SA in the control and treated groups.

A total of 67 patients were available for statistical evaluation after surgery. One patient in the control group and one patient in the treated group were lost to follow-up. One patient in the treated group, who sustained trauma at 6 months requiring surgical reduction, was excluded.

MFA significantly decreased after surgery in both groups $(p<0.0001)$. At 1 week, overcorrection was observed in $1.25 \%$ of the control group and $35.7 \%$ of the treated group $(p=0.006)$. MFA shifted from $4.16^{\circ} \pm 3.1^{\circ}$ preoperatively to $1.2^{\circ} \pm 1.4^{\circ}$ at 1 week, $1.0^{\circ} \pm 1.1^{\circ}$ at 2 weeks, $1.1^{\circ} \pm 1.4^{\circ}$ at 1 month, $1.1^{\circ} \pm 1.5^{\circ}$ at 3 months, and $1.7^{\circ} \pm 2^{\circ}$ at 1 year in the control group. In the treated group, MFA shifted from $5.7^{\circ} \pm 2.9^{\circ}$ preoperatively to $-0.34^{\circ} \pm 2.9^{\circ}$ at 1 week, $1.0^{\circ} \pm$ $1.1^{\circ}$ at 2 weeks, $0.59^{\circ} \pm 0.96^{\circ}$ at 1 month, $1.22^{\circ} \pm 0.83^{\circ}$ at 3 months, and $1.63^{\circ} \pm 0.8^{\circ}$ at 1 year. Differences between groups was significant at week $1(p=0.02)$ but showed no significance at week 2, 1 month, 3 months, and 1 year. The trend in the evolution of the MFA after surgery is shown in Fig. 3b. Long-term relative improvement of NA was better in the treated group than in the control group, as the treated group had significantly higher NA deviation than the control group and both groups ended with the similar long-term values. However, due to heterogeneity of the groups, the difference was not statistically significant $(p>0.05)$.

$\mathrm{SA}$ in the treated group changed from $170.8^{\circ} \pm 6.1^{\circ}$ to $179.2^{\circ} \pm 1.7^{\circ}$ at 1 week, $180^{\circ} \pm 1.1^{\circ}$ at 2 weeks, $180^{\circ} \pm 1.1^{\circ}$ at 1 month, and $180^{\circ} \pm 1.1^{\circ}$ at 1 year, whereas in the control group, the SA changed from $171.7^{\circ} \pm 6.2^{\circ}$ at baseline to $180^{\circ}$ $\pm 0.5^{\circ}$ at 2 weeks, $179.7^{\circ} \pm 1.3^{\circ}$ at 1 month, and $17 ., 1^{\circ} \pm 2.1^{\circ}$ at 1 year. No significant difference in SA was observed between the two groups $(p=0.44)$ (Fig. 3c).

\section{Discussion}

A high proportion of patients with congenitally deviated nose present with asymmetric facial growth [1, 14]. This relationship may be a factor for requesting rhinoplasty. In studies
Fig. 2 Placement of bidirectional barbed suture
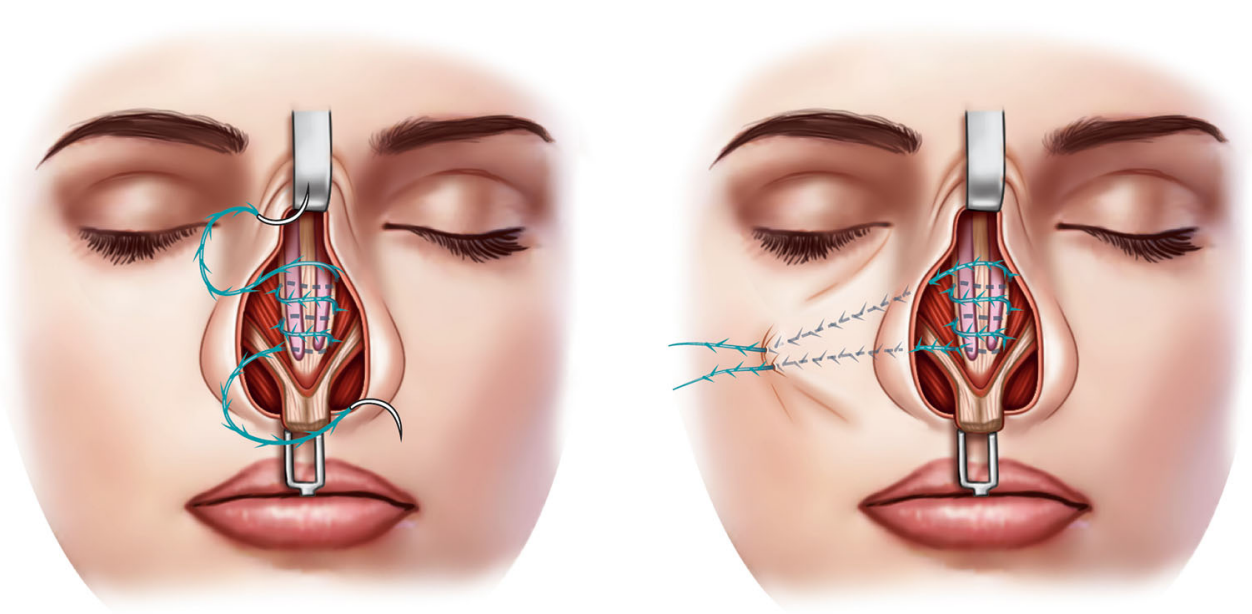
Fig. 3 a Distribution of median face axis (MFA) and scoliosis angle in the control and treated groups. b Evolution of MFA in control group and barbed suture group after surgery. c Evolution of SA in control group and barbed suture group after surgery
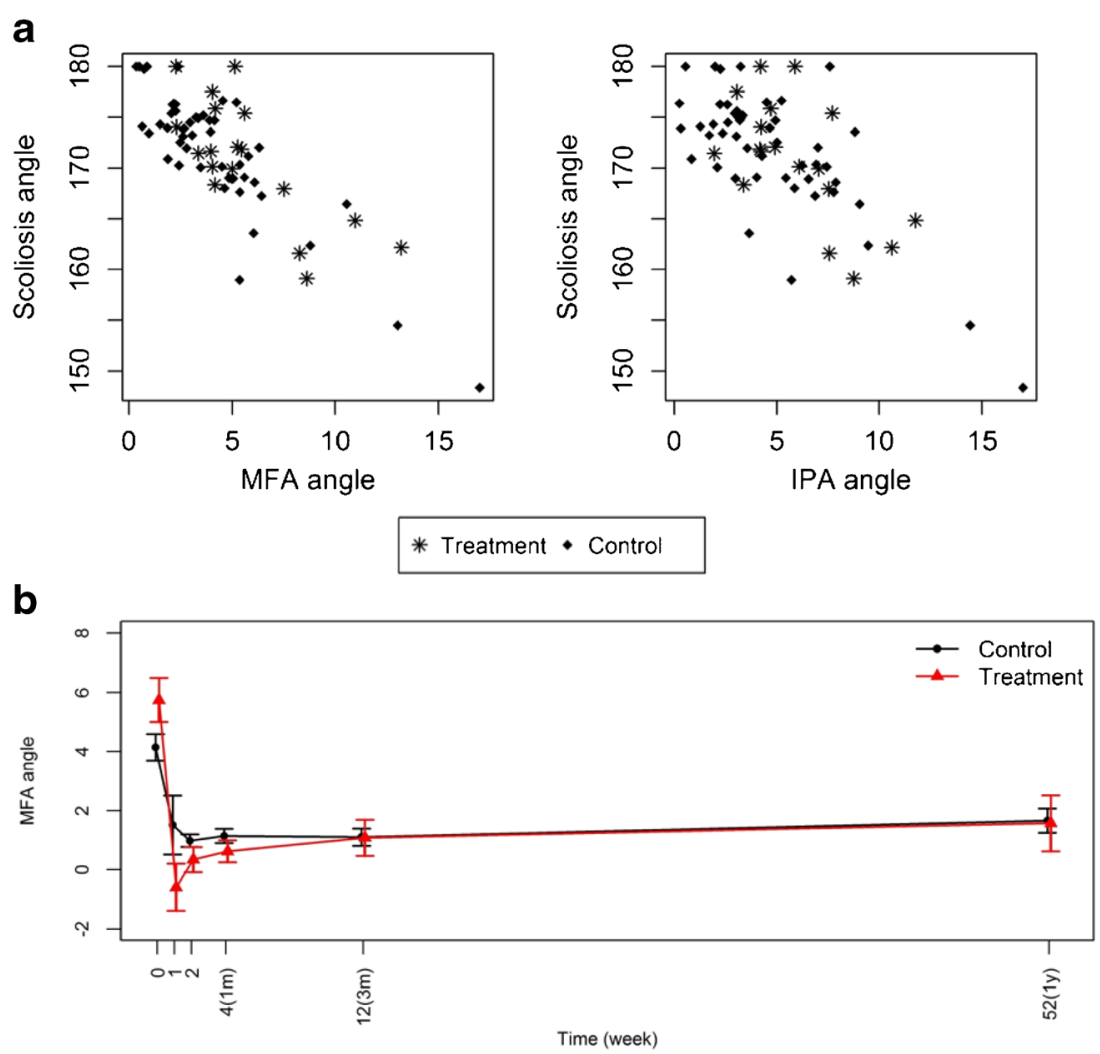

C

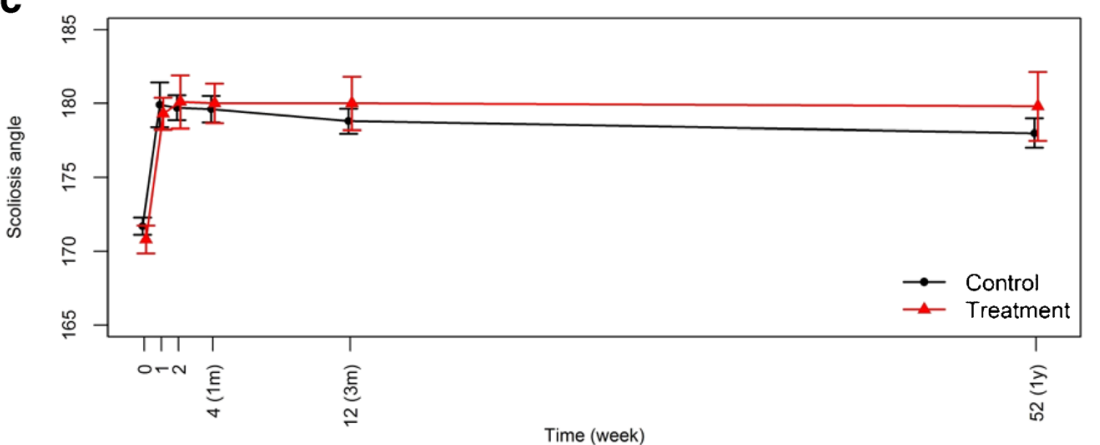

targeting patients seeking rhinoplasty, the reported rates of associated facial asymmetry varied and ranged from 30 to 97\% depending on the objective or subjective measurement of facial features $[1-3,6,7,15]$.

A simple subjective assessment for a general rhinoplasty population of 234 patients showed that $38 \%$ was perceived as having facial asymmetry [6]. When the same group is studied by objective anthropometric measurements, almost all patients (97\% of 234 patients) exhibited significant degrees of facial asymmetry [6].

In our study, the comparison between MFA and IMA demonstrates a discrepancy in $93 \%$ of patients. These measurements address only two vertical variables in the face, which should be equal if the face is strictly symmetric in its vertical dimension [16]. While these two variables do not constitute a complete anthropometric assessment, it is a very simple method of establishing vertical facial asymmetry.

However, comparison between these two variables will not detect asymmetric width of the face. In our study, IMA and MFA significantly differed $(p=0.026)$. We suggest that the angle between MFA and IMA could be used to quickly establish the degree of facial asymmetry in a vertical dimension. For clarity, we mainly focused on MFA during the follow-up period. We chose to assess MFA because the use of IMA is questionable as midfacial hypoplasia may cause orbital dystopia. Patients with orbital dystopia often spontaneously compensate by tilting their head; therefore, we believe that MFA more closely relates to objective perception.

The nasal septal traction model $[17,18]$ postulates that the nasal septum exerts a morphogenetic influence on the 
surrounding skeletal tissue. As such, a deviated septum will often induce asymmetries in the growth of maxilla and facial soft tissues including fascia, muscles, skin envelope, and fat $[2,18]$. These facial soft tissue depth asymmetries have been reported at a high frequency, affecting approximately $50 \%$ of landmarks acquired from a contemporary adult general Caucasian population by CT and 3D analysis. [19, 20] This frequency is much higher in a population of rhinoplasty candidates $[6,7]$.

Although recurrence of nasal deviation is a major drawback of surgery, only a few authors have reported their own experiences and success rates quantitatively. Cho and Jang [21] reported successful (described as excellent or good) outcomes in $80.2 \%$ of 631 patients, and unsuccessful (fair or no change) outcomes in $19.8 \%$ of patients, with a $6.5 \%$ revision rate. Erdem et al. [22] reported excellent or good results in $58.3 \%$ of 120 patients, and moderate or poor results in $41.7 \%$ of the patients. The reported deviation angles were $6.8^{\circ}$ and $152^{\circ}$ preoperatively and $2.0^{\circ}$ and $173^{\circ}$ postoperatively with Iand $\mathrm{C}$-shaped crooked noses, respectively.

Okur et al. [23] found deviation angles of $7.6^{\circ}$ and $147^{\circ}$ preoperatively and $1.9^{\circ}$ and $167^{\circ}$ postoperatively in 27 patients with I- and C-shaped crooked noses, respectively. Ellis and Gilbert [24] reported that the correction rates were $75 \%$ for rhinion deformities without any detail. Hussein et al. [25, $26]$ reported a preoperative mean NA deviation of $10.7 \pm 3.05$ and a postoperative mean NA deviation of $1.101 \pm 0.904$ in 15 I-shaped patients. Pontius et al. [16] reported on 70 patients (mean follow-up of 13.1 months) with improvement in all patients, but 7 patients presented noticeable persistent deviation and 3 patients elected revision surgery.

To our best knowledge, only one study reported long-term results in a series of 264 patients with severe nasal deviation and compared spreader grafting techniques in a randomized study. Barone et al. [25, 26] evaluated results of different types of spreader grafts or flaps and found out that the use of both spreader flap and spreader graft obtained the best long-term outcome for adequate correction of nasal deviation. SA was corrected from preoperative value $166.2 \pm 3.8^{\circ}$ to $178.5 \pm 1.5^{\circ}$ in the group with both spreader flaps and grafts.

Certain assumptions have been made on the etiology of nasal shift recurrence, such as bone or cartilage "memory," scar retraction, splinting, or facial envelope effect, and we briefly criticize them. Immediate nasal deviation recurrence would likely be linked to inadequate surgery. Persistent deviation of the nasal septum, unaddressed discrepancies in nasal bone lengths, uncorrected asymmetries in the upper lateral cartilages or nasal tip, and inadequate bony foundation [27] are major causes of surgical failures. Modifications of splinting techniques may affect the width of nasal bones but they cannot affect the NA due to the lack of support on the facial skeleton, even if advocated by some authors [28].
If the surgeon is experienced and uses advanced techniques, these drawbacks should be minimized. As demonstrated by Barone et al. [25, 26] spreader grafts and flaps probably improve the long-term results. However, despite the adequacy of the technique used, the nose may not maintain its correct position during the early postoperative stage, and it may deviate to its previous position to some extent during the first months.

An underestimated factor, in our opinion, is the extrinsic factor, namely the facial envelope effect [3]. Although most authors postulate that the long-term stability of the nose is derived from rigid or semi-rigid intrinsic structures, they also acknowledge the importance of facial muscles and soft tissues during development. A well-known example of soft tissue interaction is encountered with nasal growth in cleft lip patients [29]. The pattern of deformities is a result of both the asymmetric bony base and the unbalanced biomechanical forces acting in the nose. During development, any asymmetry of muscle action or skin tension will cause deformities of the nose and face as observed in cleft lip nose, Parry-Romberg syndrome, and torticollis. The paradox is that little attention is paid to the same tissues and their changes after rhinoplasty in a congenitally deviated nose.

Rohrich et al. [30] and Hafezi et al. [31] recognized that the nasal deviation is closely related to facial asymmetry and that the nose tends to deviate from the wider side of the face toward the hypoplastic side of the face.

As a result, when the nose is set at the midline after rhinoplasty, additional tension is created on the hypoplastic side of the face, while the wider side of the face loosens (Fig. 4). The tension of the narrower side will even increase with facial expressions and smiling. Over time, these tissues gradually stretch and accommodate. This soft tissue constraint may explain at least partially why a nose that is perfectly straight after surgery may re-deviate progressively toward the hypoplastic side over a relatively short period [3].

To test this facial envelope hypothesis, we designed a new surgical technique using barbed sutures anchored in the midfacial soft tissues. Traditional sutures could not be used in the face due to constricting loops or knots and possible visibility. However, barbed sutures offer the ability to secure tissues without relying on such knots or loops. They also provide resistance, which is distributed along the whole line of the suture, avoiding possible ischemia of the tissues. They were developed by surgeons John Alcamo, Alan McKenzie, and Gregory Ruff [32] and have gained considerable popularity in laparoscopic, orthopedic, and plastic surgeries. Their field of application encompasses wound closure but also tissue suspension. The nature of the suture and its resorption time influence the holding strength over time, although the authors claim that collagen formation occurs along the barbs [33] and maintains its advantage over time. 


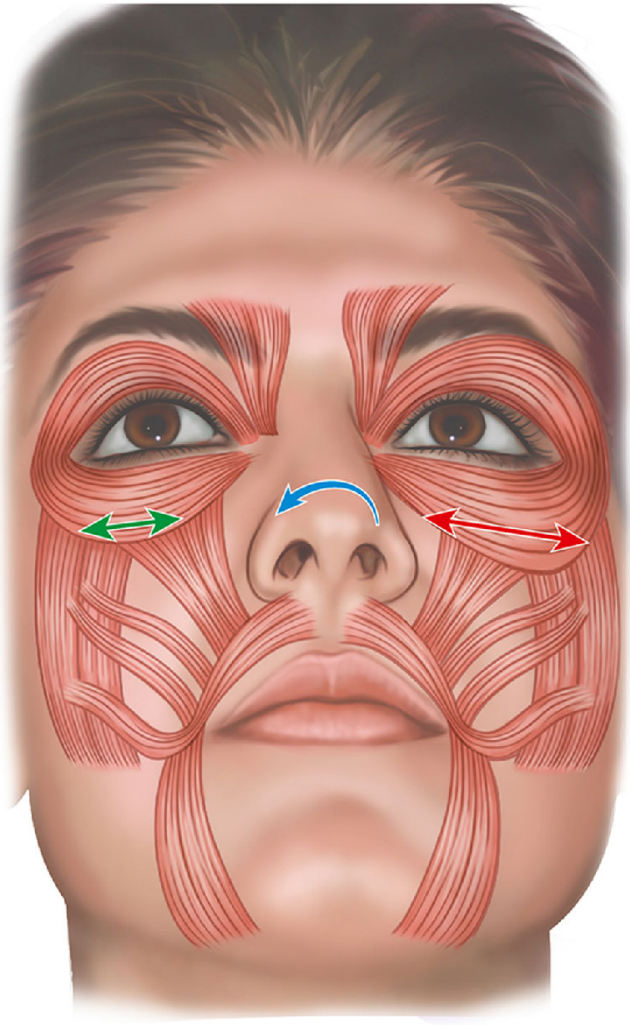

Fig. 4 Modification of tensile forces in facial soft tissue when medializing the nose

The distribution of the barbs, their angle along the suture, and the delivery method of the suture influence the holding strength of the suture. A needle larger than the suture or the introduction of the suture through a hollow delivery needle will create a channeling effect and compromise the ability of the barbs to hold [34]. Barbed sutures in rhinoplasty have been described by Bradford et al. [35] and Allen [36] for fixation of spreader grafts, but the claimed advantage was practical and not conceptual, i.e., avoidance of tying knots in a limited space.

In this study, we anchored the nose at the midline (Fig. 2.), compensating asymmetric tensile strengths resulting from the medialization of the nose. The tension in the suture was adjusted at the end of surgery (Fig. 5). A possible dynamic effect was even possible as the tension increased during facial expressions. We were able to observe a dimple in the cheek either at rest or during changes in facial expressions in onethird of the patients, indicating that the traction effect of the suture was present at rest or during facial expressions (Fig. 6). We were not able to measure any movement of the nose during forceful expressions during the early postoperative period.

No side effects were observed. The dimple that was noticeable in some patients at 1 and 2 weeks postoperatively disappeared without sequela, and no visibility of the suture exit point was observed. None of the patients presented with sensory impairment in the infraorbital nerve area or had facial impairment.

The pattern of slight re-deviation of the nose was definitely altered during the first weeks. Moreover, slight overcorrection was observed in one-third of the patients at weeks 1 and 2. No statistically significant long-term advantage was observed. The treated group showed more severe deviation than the control group - as this was a non-randomized pilot studyand the improvement indeed was better in the treated group in terms of relative improvement, but it did not reach significance over the long term. In this pilot study, we used poliglecaprone sutures, which hold $50 \%$ of its tensile strength at 1 week and $0 \%$ at 3 weeks [37]. Although some authors claim collagen formation along the barbs [33], we observed that the loss of advantage parallels the resorption of the poliglecaprone material.

Altogether, we suggest that rigging the nose during the healing phase may counteract the unbalanced tension of the soft tissue. We hypothesized that this procedure could help in stabilizing the nose, provided that all structural factors-i.e., advanced septoplasty, spreader grafts, correction of bony, and cartilaginous asymmetries - have been adequately addressed. As the present study was a pilot study evaluating the feasibility of the technique, the absence of side effects, and the possibility of a positive effect, we did not design a randomized study. This explains that the treated group presented with more severe deviation and scoliosis than the control group and that the statistical evidence was significant only at week
Fig. 5 Sutures exiting the cheek before tensioning

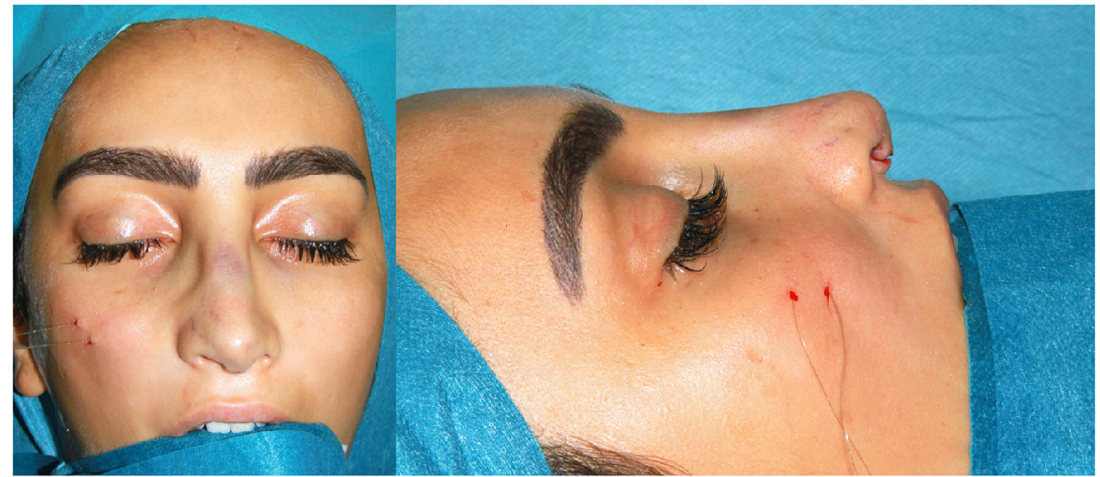




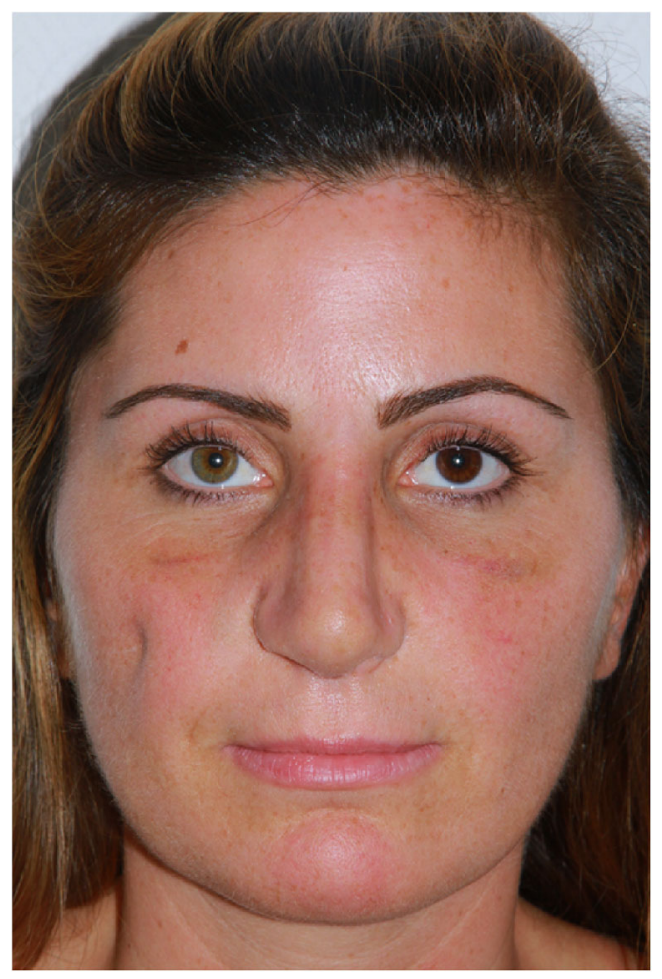

Fig. 6 Postoperative picture at day 6 post-surgery demonstrating a dimple at the insertion of barbed sutures in the right cheek and showing slight overcorrection of nasal axis

1 and week 2. However, the results of this pilot study were encouraging; no side effects were observed and the minimal time was added to the overall procedural time. These elements indicate that further evaluation of the technique using barbed sutures should be conducted and that larger, randomized series should be evaluated. Longer lasting sutures such as barbed polydioxanone should as well be investigated in search for a definitive improvement in the long term.

\section{Conclusions}

Postoperative recurrence of nasal deviation is observed in a high number of patients and gradually evolves during the first months before definitive stabilization. We suspect that preexisting asymmetry of the face and related facial envelope uneven tension plays a notable role in the etiology of recurrence. The asymmetry present in the facial soft tissues will result in the imbalance of the elastic and muscular forces after the nose is set back at the midline. Stabilization of the nose in the soft tissues of the cheek contralateral to the deviation using barbed sutures is technically easy and has no side effects. Overcorrection of the NA was obtained in one-third of our patients at week 1 , and a gradual slight re-deviation was observed during the first 3 months. Significant improvement of NA was obtained during the first weeks, but no clear definitive advantage over the long term was demonstrated. These encouraging results and the use of longer lasting polydioxanone sutures should be investigated in a larger randomized study.

Acknowledgments Statistics. Donneau AF. Dept of Biostatistics, Liege University, Liege, Belgium

Author contributions Study concept and design: Goffart Y

Surgery and follow-up: Goffart Y

Acquisition of data: Goffart Y, Remacle S

Analysis and interpretation of data: Goffart Y, Remacle S

Drafting of the manuscript: Goffart Y

Graphic edition: Goffart Y

\section{Compliance with ethical standards}

Conflict of interest Authors Yves LJ Goffart and Sarah Remacle declare that they have no conflicts of interest.

Ethical approval All procedures performed in the study were in accordance with the ethical standards of the institutional and national research committee and with the 1964 Helsinski Declaration and its later amendments. Institutional review board CHR Citadelle Belgium 412 reviewed the protocol and approved the study.

Informed consent Informed consent was obtained from all individual participants included in the study.

Patient consent Patients signed informed consent regarding publishing their data and photographs. Additional informed consent was obtained from all individual participants whose identifying information is included in the article.

Open Access This article is licensed under a Creative Commons Attribution 4.0 International License, which permits use, sharing, adaptation, distribution and reproduction in any medium or format, as long as you give appropriate credit to the original author(s) and the source, provide a link to the Creative Commons licence, and indicate if changes were made. The images or other third party material in this article are included in the article's Creative Commons licence, unless indicated otherwise in a credit line to the material. If material is not included in the article's Creative Commons licence and your intended use is not permitted by statutory regulation or exceeds the permitted use, you will need to obtain permission directly from the copyright holder. To view a copy of this licence, visit http://creativecommons.org/licenses/by/4.0/.

\section{References}

1. Chatrath P, De Cordova J, Nouraei SA, Ahmed J, Saleh HA (2007) Objective assessment of facial asymmetry in rhinoplasty patients. Arch Facial Plast Surg 9(3):184-187

2. Hartman C, Holton N, Miller S, Yokley T, Marshall S, Srinivasan S, Southard T (2016) Nasal septal deviation and facial skeletal asymmetries. Anat Rec 299(3):295-306

3. Goffart YLJ, Remacle S (2019) Rhinoplasty in the deviated nose: patterns of recurrence and role of facial asymmetry. Eur J Plast Surg 42:569-576 x

4. Dayan SH, Arkins JP (2012) The subliminal difference: treating from an evolutionary perspective. Plast Reconstr Surg 129(1): $189 \mathrm{e}-190 \mathrm{e}$ 
5. Zaidel DW, Cohen JA (2005) The face, beauty, and symmetry: perceiving asymmetry in beautiful faces. Int J Neurosci 115(8): $1165-1173$

6. Carvalho B, Ballin A, Becker R, Berger C, Hurtado J, Mocellin M (2012) Rhinoplasty and facial asymmetry: analysis of subjective and anthropometric factors in the Caucasian nose. Int Arch Otorhinolaryngol 16(4):445-451

7. Yi JS, Jang YJ (2015) Frequency and characteristics of facial asymmetry in patients with deviated noses. JAMA Facial Plast Surg 17(4):265-269

8. Cottle M, Loring R (1948) Surgery of the nasal septum; new operative procedures and indications. Ann Otol Rhinol Laryngol 57(3): 705-713

9. Gubisch W (1995) The extracorporeal septum plasty: a technique to correct difficult nasal deformities. Plast Reconstr Surg 95(4):672682

10. Sykes JM, Kim J, Shaye D, Boccieri A (2011) The importance of the nasal septum in the deviated nose. Facial Plast Surg 27(5):413421

11. Boccieri A (2013) The crooked nose. Acta Otorhinolaryngol Ital 33(3):163-168

12. Byrd HS, Salomon J, Flood J (1998) Correction of the crooked nose. Plast Reconstr Surg 102(6):2148-2157

13. Courtiss EH (1978) Septorhinoplasty of the traumatically deformed nose. Ann Plast Surg 1(5):443-459

14. Kim YM, Rha KS, Weissman JD, Hwang PH, Most SP (2011) Correlation of asymmetric facial growth with deviated nasal septum. Laryngoscope. 121(6):1144-1148

15. Barone M, Cogliandro A, Salzillo R, List E, Panasiti V, Tenna S, Persichetti P (2019) Definition of "gender angle" in Caucasian population. Aesthet Plast Surg 43(4):1014-10120

16. Pontius AT, Leach JL Jr (2004) New techniques for management of the crooked nose. Arch Facial Plast Surg 6(4):263-266

17. Scott JH (1954) The growth of the human face. Proc R Soc Med 47(2):91-100

18. Holton NE, Yokley TR, Figueroa A (2012) Nasal septal and craniofacial form in European- and African-derived populations. J Anat 221(3):263-274

19. Thiemann N, Keil V, Roy U (2017) In vivo facial soft tissue depths of a modern adult population from Germany. Int J Legal Med 131(5):1455-1488

20. Toneva D, Nikolova S, Georgiev I, Harizanov S (2018) Facial soft tissue thicknesses in Bulgarian adults: relation to sex, body mass index and bilateral asymmetry. Folia Morphol (Warsz) 77(3):570 582

21. Cho GS, Jang YJ (2013) Deviated nose correction: different outcomes according to the deviation type. Laryngoscope. 123(5): $1136-1142$
22. Erdem T, Ozturan O (2008) Objective measurement of the deviated nose and a review of surgical techniques for correction. Rhinology. 46(1):56-61

23. Okur E, Yildirim I, Aydogan B, Akif KM (2004) Outcome of surgery for crooked nose: an objective method of evaluation. Aesthet Plast Surg 28(4):203-207

24. Ellis DA, Gilbert RW (1991) Analysis and correction of the crooked nose. J Otolaryngol 20(1):14-18

25. Hussein WKA, Baker SR, Ismail AS, Elwany S (2015) Crooked nose: the asymmetric face. EJENTAS. 16(3):237-242

26. Barone M, Cogliandro A, Salzillo R, Colapietra A, Alessandri Bonetti M, Morelli Coppola M, List E, Ciarrocchi S, Tenna S, Persichetti P (2019) Role of spreader flaps in rhinoplasty: analysis of patients undergoing correction for severe septal deviation with long-term follow-up. Aesthet Plast Surg 43(4):1006-1013

27. Yao F, Lawson W, West Reich RW (2009) Effect of midfacial asymmetry on nasal axis deviation: indications for use of the subalar graft. Arch Facial Plast Surg 11(3):157-164

28. Tugrul S, Dogan R, Kocak I, Ozturan O (2015) Asymmetrically pressing nasal splint for crooked nose deformity. J Craniofac Surg 26(1):180-185

29. Hollier L, Kim J, Grayson BH, McCarthy JG (2000) Congenital muscular torticollis and the associated craniofacial changes. Plast Reconstr Surg 105(3):827-835

30. Rohrich R, Villanueva N, Small K, Pezeshk R (2017) Implications of facial asymmetry in rhinoplasty. Plast Reconstr Surg 140(3): $510-516$

31. Hafezi F, Naghibzadeh B, Nouhi A, Yavari P (2010) Asymmetric facial growth and deviated nose: a new concept. Ann Plast Surg 64(1):47-51

32. Matarasso A, Ruff GL (2013) The histor y of barbed sutures. Aesthet Surg J 33(3):12S-16S

33. Fukaya M (2006) A new method of face lift using barbed threads: X-tosis. J Jpn Soc Aesthet Surg 43:173

34. Leung JC (2002) Optimized delivery needle. Quill Medical, Research Triangle Park

35. Bradford BD, Asher SA, Ardeshirpour F (2016) Endonasal (closed) rhinoplasty technique: securing spreader grafts with barbed suture. JAMA Facial Plast Surg 18(5):395-396

36. Allen DR (2007) Use of barbed sutures for fixation of spreader grafts in rhinoplasty: a novel technique. Biomed J Sci Tech Res 1(7)

37. Greenberg JA, Clark RM (2009) Advances in suture material for obstetric and gynecologic surgery. Rev Obstet Gynecol 2(3):146158

Publisher's note Springer Nature remains neutral with regard to jurisdictional claims in published maps and institutional affiliations. 